\title{
Impactos colaterais da integração financeira: o caso brasileiro entre 1980 e 2009
}

\author{
Milton André Stella ${ }^{1}$ \\ Ronald Otto Hillbrecht ${ }^{2}$ \\ Alexandre Alves Porsse ${ }^{3}$
}

Resumo Este artigo analisa os impactos colaterais do processo de integração financeira do Brasil. Para tanto, o principal aspecto analisado foi o comportamento da volatilidade do Produto Interno Bruto (PIB) entre 1980 e 2009. A análise dividiu o período em quatro subperíodos, cada um incorporando ao menos uma mudança institucional ou de política econômica relevante. Os resultados indicaram uma redução sistemática da volatilidade do PIB brasileiro após 1991, período a partir do qual o País é considerado financeiramente integrado ao resto do mundo, e a hipótese de significância estatística da mudança de comportamento da volatilidade é confirmada por um modelo GARCH.

Palavras-chave: Integração financeira. Efeitos Colaterais. Reformas. Volatilidade. JEL: F33, F43, F44.

\section{Collateral impacts of financial integration: the brazilian case from 1980 to 2009}

\begin{abstract}
This article aims to analyze the collateral impacts of the Brazilian financial integration process. In order to reach this goal, the main considered aspect was the behavior of the GDP volatility between 1980 and 2009. The analysis divided the series in four sub periods with at least one relevant political or institutional change in each one of them. Results indicate a systematic decrease in Brazilian GDP volatility after 1991, period in which the country is considered financially integrated with the rest of the world. A GARCH model confirms that changes in the volatility behavior are significantly different from zero.
\end{abstract}

Keywords: Financial integration. Collateral Effects. Reforms. Volatility. JEL: F33, F43, F44.

\footnotetext{
1 Prof. Pontifícia Universidade Católica do RS - PUCRS. Doutor UFRGS - Universidade Federal do Rio Grande do Sul. E-mail: milton.stella@pucrs.br

2 Prof. Universidade Federal do RS - UFRGS. Ph.D. University of Illinois - Urbana-Champaign.

E-mail: ottohill@ufrgs.br

3 Prof. Universidade Federal do Paraná - UFPR. Doutor UFRGS - Universidade Federal do Rio Grande do

Sul. E-mail: porsse@gmail.com
} 


\section{Introdução}

O novo ciclo de integração financeira iniciado na segunda metade da década de 1980, incrementando o fluxo de capitais internacional revigorou o debate acerca dos efeitos deste processo sobre o desempenho econômicos dos países. O debate acadêmico se divide entre os que acreditam que a maior liberdade dos fluxos de capitais é uma poderosa ferramenta para aumentar a eficiência da alocação de recursos produtivos, e aqueles que crêem que este processo é o principal responsável pelas crises financeiras e fugas de capitais ocorridas nos países em desenvolvimento neste mesmo período.

O primeiro grupo corrobora as previsões do modelo neoclássico, introduzido pelo seminal artigo de Solow (1956), apontando benefícios inequívocos para os países que ampliavam seu grau de abertura financeira, principalmente os países em desenvolvimento que seriam os grandes receptores desse fluxo. Pelo modelo neoclássico, a integração financeira, representada pelo grau de liberalização da conta de capital, permitiria uma alocação mais eficiente dos recursos gerando uma série de benefícios. De acordo com esse modelo, os recursos deveriam fluir dos países desenvolvidos, abundantes em capital, nos quais os retornos são baixos, para os países em desenvolvimento, naturalmente com carência de capital e que, portanto, ofereceriam maiores retornos para esse fator. O fluxo de recursos reduziria o custo do capital e, assim, estimularia um aumento temporário nos investimentos que elevaria permanentemente sua renda ${ }^{1}$. Essa posição aparece em diversos estudos, entre eles Fisher (1998), Obstfeld (1998), Rogoff (1999) e Summers (2000).

Por outro lado, outros autores (Rodrik, 1998; Eichengreen, 2001; Edison et al., 2004) argumentam que o modelo neoclássico tem validade somente quando se assume que não existem outras distorções na economia, exceto barreiras ao fluxo de capitais. Ou seja, o modelo estaria partindo de hipóteses muito simplificadoras, uma vez que países em desenvolvimento apresentam uma série de outras imperfeições que podem afetar seu crescimento. Rodrik (1998) argumenta que as evidencias empíricas não confirmam a existência de correlação positiva entre abertura da conta de capital e a taxa de crescimento do país. No entanto, afirma que os custos da abertura de capital são claros e aparecem na forma de crises externas recorrentes.

Edison et al. (2004) e Prasad et al. (2003) elaboraram revisões da literatura acerca do tema, e constataram que apenas três estudos do conjunto revisado apresentavam correlação significativa entre integração financeira e crescimen-

\footnotetext{
1 Feenstra e Taylor (2008) chamam o modelo neoclássico de modelo "ingênuo". Os autores mostram que o modelo considera hipóteses que não são verdadeiras e que isso altera algumas das suas mais importantes conclusões. A principal falha é considerar que os países possuem as mesmas funções de produção, quando na prática isso não é verdadeiro. Com funções de produção diferentes, o produto marginal do capital pode não ser maior nos países em desenvolvimento do que nos desenvolvidos, para diferentes níveis de capital per capita. Diversos fatores podem afetar o produto marginal do capital, entre eles a qualidade das instituições e do capital humano. Esta é uma das possíveis razões para o baixo fluxo de capitais migrando dos países ricos para os em desenvolvimento.
} 
to econômico ${ }^{2}$. Esse último conclui categoricamente que a literatura econômica sobre o tema, até aquele momento, não fornecia evidências robustas que permitissem afirmar que a maior abertura financeira de um país aumentaria a sua taxa de crescimento.

Henry (2006), entretanto, critica essa conclusão com um argumento bastante perturbador. Sua argumentação é que muitos estudos empíricos não encontram evidências de relação positiva entre integração financeira e crescimento, mas o grande ponto é que estes estudos não são construídos adequadamente para testar a validade da teoria neoclássica. A maioria deles faz meramente regressões cross-section entre abertura da conta de capital e crescimento, mas testando efeitos nas taxas de crescimento de longo prazo para uma amostra de países. Acabam testando, portanto, efeitos permanentes nas taxas de crescimento dos receptores do capital, e não variações temporárias como sugere o modelo neoclássico. Neste, o que muda de forma permanente é o nível de renda per capita, mas não a sua taxa de crescimento.

Por sua vez, Kose et al. (2006) argumenta que a contribuição da abertura da conta de capital pode trazer benefícios para o crescimento econômico de maneira indireta. Ou seja, os benefícios não viriam pelos canais amplamente defendidos, como o aumento de recursos para financiamento de investimentos domésticos (argumento da eficiência alocativa que está na essência do modelo neoclássico). Assim, o que os autores argumentam é que a integração financeira gera um conjunto de benefícios colaterais potenciais como, por exemplo, desenvolvimento do setor financeiro, disciplina na política macroeconômica, aumento da eficiência em função do acirramento da competição entre as empresas e melhores práticas do setor público. Essa é uma possível explicação do porquê muitos estudos indicam ausência de relação entre abertura de capital e crescimento, quando variáveis que controlam alterações nos canais apresentados acima são introduzidas no modelo. Seguindo a mesma lógica da existência de efeitos diretos e indiretos relacionados à integração financeira, Ranciere et al. (2006) encontram evidências que apontam para impactos positivos sobre a taxa de crescimento do PIB (chamado de efeito direto), mas efeitos negativos em função do aumento da propensão a crises financeiras (chamado de efeito indireto) ${ }^{3}$. Os autores concluem que os efeitos positivos sobre o crescimento superam largamente as perdas associadas à ocorrência de crises financeiras.

Além disso, Kose et al. (2006) conseguem fechar algumas lacunas importantes da literatura relacionada aos impactos da integração financeira que estimulam posições divergentes quanto aos seus benefícios e custos. Em primeiro lugar, estabelecem uma relação entre efeitos da integração financeira e seus aspectos institucionais. Em princípio, os efeitos podem ser positivos ou negativos, 2 Edison et al. (2004) revisa dez estudos e Prasad et al. (2003) revisa quatorze pesquisas que examinam as relações entre abertura de capital e crescimento.

3 Kaminsky e Reinhart (1998) e Demirguc-Kunt e Detragiache (1998 apud RANCIERE et al. 2006) encontram evidências que há aumento da propensão a ocorrência de crises bancárias e monetárias após a integração financeira. 
no que tange à redução de risco e alocação de recursos, mas dependendo da qualidade das instituições locais e políticas macroeconômicas adotadas, a probabilidade do efeito ser positivo pode variar. Em segundo lugar, o horizonte temporal da análise passa a desempenhar um papel fundamental para se computar os ganhos ou perdas do processo.

Quando passamos a considerar que os efeitos de curto prazo e de longo prazo do processo de integração financeira podem ser distintos, a argumentação aparentemente contraditória dos parágrafos acima passa a ter uma lógica muito interessante. Uma parte importante da literatura entende que os maiores beneficiados com a intensificação da integração financeira são os países em desenvolvimento de renda média ou, alternativamente, considerados de nível institucional intermediário ${ }^{4}$. Isso significa que países que possuem instituições sólidas (mercado financeiro desenvolvido e segurança jurídica dos contratos), assim como aqueles que adotam políticas macroeconômicas sólidas (inflação baixa, equilíbrio fiscal, livre comércio) tendem a capitalizar bons frutos com a integração, enquanto que os países que ainda não alcançaram esse estágio tendem a sofrer oscilações bruscas no seu nível de renda e aumentam a probabilidade de sofrerem crises financeiras de grandes proporções.

Nestas condições, os países deveriam primeiro desenvolver suas instituições e adotar políticas macroeconômicas sólidas antes de promover a integração dos seus mercados financeiros. Entretanto, se a abertura financeira funcionar como um catalisador de reformas, os países podem absorver os ganhos da integração, mesmo que se tenha um custo inicial (aumento da volatilidade de variáveis econômicas). Neste caso, mesmo que num primeiro momento o país observasse o lado negativo do processo, como flutuações bruscas de câmbio, oscilações da renda e do consumo, a longo prazo, esse mesmo processo acabaria por incentivar as reformas que promoveriam aperfeiçoamentos institucionais que fariam com que a face positiva da integração predominasse. A construção de instituições sólidas, disciplina de mercado e desenvolvimento do setor financeiro tomam tempo, e estes são importantes canais pelos quais crescimento econômico originado pela entrada de capitais se manifesta ${ }^{5}$.

Com isso, em termos teóricos, podemos conviver com situações em que a integração causa crises e casos em que temos efeitos positivos, como aceleração do crescimento econômico e redução da inflação. Entretanto, no caso dos países em desenvolvimento, poderá haver um predomínio dos efeitos negativos no curto prazo, mas no longo prazo, uma vez que o país tenha tido tempo suficiente para promover as reformas pró-mercado necessárias, os efeitos positivos devem prevalecer.

O objetivo deste estudo é analisar se o caso brasileiro pode ser um exemplo de país em desenvolvimento que sofre o processo de crise e adaptação ao ${ }^{4}$ Ver Prasad et al. (2006).

${ }^{5}$ Cipriani e Kaminsky (2006) afirmam que os mercados financeiros se tornam menos erráticos após a integração financeira. Kose et al. (2009) destacam o papel das instituições para o desempenho econômico. Mishkin (2006) apresenta uma ampla revisão desta literatura. 
mercado de capitais integrado descrito pela teoria dos efeitos colaterais da integração financeira. Será que o processo de integração do Brasil pode servir de referência para a defesa da tese de que os países em desenvolvimento tendem a ter benefícios a longo prazo, decorrentes do processo de integração financeira? Centraremos a análise no comportamento da volatilidade do PIB, mas também iremos registrar se houve alguma alteração significativa na condução da política econômica após o período em que o país passa a ter fluxo de capitais livre.

Outros estudos já abordaram os impactos do processo de abertura financeira ocorrido no Brasil nas últimas décadas, mas nenhum enfatizou os seus impactos indiretos, apesar de alguns de seus aspectos serem considerados marginalmente. Goldfajn e Minella (2005) fazem uma excelente análise de fatos estilizados relacionados às alterações das regras de controles de capitais e ao comportamento dos fluxos de capitais a partir da década de 90 até 2004. Os autores observam que ocorreu uma mudança significativa nos padrões de acumulação de dívida externa após a abertura, e principalmente após a migração para o regime de câmbio flutuante. $O$ efeito foi uma acentuada redução na emissão de títulos de dívida externa pelo setor privado, em função da própria redução da oferta de recursos, mas também pela eliminação das garantias implicitas de paridade para os tomadores, que viam na flutuação do câmbio mais um elemento de risco.

O estudo também aponta uma alteração significativa no perfil do financiamento externo, com os fluxos de investimento externo direto superando os investimentos em portfólio. Estes fluxos de entrada financiaram predominantemente os déficits em conta-corrente do período. A análise abordou um dos aspectos propostos no nosso estudo. Observou-se que a volatilidade do consumo agregado (medido em percentual do PIB) foi menor do que nos anos 8o. Por fim, o estudo apontou as principais causas de interrupções bruscas no fluxo de capitais. Os principais fatores são de ordem doméstica, como o aumento do risco país (medido pelo Emerging Markets Bond Index - EMBI) uma vez que acaba induzindo redução da entrada de capitais, aumento da taxa de juros, moeda mais depreciada e queda no produto. Os autores concluem que estas são evidências da importância de se construir bons fundamentos nos países emergentes.

Carvalho e Garcia (2006) mostram, a partir do caso brasileiro, que controles de capitais acabam sendo pouco eficientes em países cujos mercados de capitais são sofisticados. Conclusão semelhante chegam Cardoso e Golfajn (1998). Os autores mostram que o governo brasileiro reage fortemente aos movimentos de capital, aumentando as restrições a entrada em momento de forte influxo de capital e reduzindo estas restrições em momentos de escasses de recursos, mas que estas restrições são parcialmente eficazes para alterar os níveis e a composição destes fluxos sem, entretanto, gerarem efeitos de longo prazo. Garcia e Barcinski (1998), estudando os determinantes do fluxo de capitais 
para o Brasil, concluem que até 1998 o diferencial de taxas de juros entre o Brasil e o resto do mundo foi o fator determinante para a atração do enorme volume de capital registrado, e que os controles de capitais aplicados foram somente em parte eficazes. A mesma conclusão é encontrada em Garcia e Valpassos (1998).

Pires (2006) conclui que a abertura financeira ocorrida no Brasil implicou na imposição de limites à utilização da política fiscal para intervir nos ciclos econômicos. O governo passou a adotar uma política fiscal mais conservadora.

Recentemente, Tófoli et al. (2008), utilizando uma mostra de empresas brasileiras de capital aberto, encontram evidênciasde de que após a abertura financeira houve um aumento médio de aproximadamente $1,7 \%$ ao ano na taxa de crescimento do estoque de capital das firmas, principalmente devido à queda do custo do capital acionário. Ou seja, encontram evidências dos movimentos da eficiência alocativa demonstrados no modelo neoclássico. Entretanto, embora encontrem evidências da alocação eficiente entre o exterior e o Brasil, não conseguem obter evidências favoráveis de alocação eficiente entre os setores da economia brasileira.

Este artigo está organizado da seguinte forma. Além desta introdução, na segunda seção faremos uma breve descrição dos resultados apontados pela teoria no que se refere aos efeitos indiretos da integração financeira. $\mathrm{Na}$ terceira seção apresentaremos os testes empíricos para o caso brasileiro. Por fim, na seção quatro apresentaremos nossas considerações finais.

\section{Efeitos indiretos da integração financeira}

Henry (2000a), ao buscar explicação para o aumento dos preços dos ativos nos países que promovem abertura financeira, argumenta que a mudança de uma economia financeiramente fechada para outra com abertura da conta de capital, normalmente coincide com quatro reformas: (1) estabilização macroeconômica, (2) abertura comercial, (3) privatizações e (4) redução de controles de câmbio. $\mathrm{O}$ autor também chama atenção para o fato dos testes tradicionais não controlarem para os efeitos indiretos da abertura de capital, e com isso gerarem estimadores enviesados, na medida em que parte dos efeitos da abertura seria responsabilidade das reformas ocorridas ao mesmo tempo ou nos períodos subseqüentes ao fato. Desta forma, o referido artigo reforça a idéia de que existe uma relação entre a abertura da conta de capital e a probabilidade de ocorrerem reformas no país e que pelo menos parte dos resultados observados nas taxas de crescimento pode derivar destas transformações. A importância destas reformas já foi apresentada por uma série de estudos. Os efeitos benéficos sobre preços dos ativos, investimento e crescimento, derivados da estabilização da inflação, por exemplo, foram con- 
firmados em Easterly (1996), Bruno e Easterly (1998), Calvo e Végh (1998), Henry (2000b) e Fischer et al. (2002). Por sua vez, os impactos da abertura comercial são abordados por Sachs e Warner (1995), Krueger (1997/1998), Frankel e Romer (1999) e Wacziarg e Welch (2003). Por fim, os efeitos das privatizações foram tratados por Megginson (2001).

Pela lógica descrita acima, os efeitos da abertura da conta de capital não são imediatos, uma vez que os canais que potencializam os benefícios da integração são indiretos, fundamentalmente derivados de processos de reformas estruturais. A aceleração das taxas de crescimento ocorre com alguma defasagem de tempo. Portanto, o tempo médio entre a abertura financeira e a aceleração da taxa de crescimento dos países pode estar relacionado à resistência dos países em levarem adiante seus processos de reformas.

A análise segue argumento semelhante ao proposto por Krugman (2002), que defende que, a longo prazo, a integração tende a resolver os problemas que cria inicialmente, como, por exemplo, aumento da volatilidade da entrada e saída de recursos e oscilação do consumo. Martinez et al. (2004) argumentam que as crises são o preço que se paga para ter rápido crescimento uma vez que a garantia dos contratos esteja estabelecida. Argumentos semelhantes são apresentados por Kaminsky e Schmukler (2003) e Bussiere e Fratzscher (2004).

Seguindo esse conjunto de evidências, poderemos ver coexistindo dois fenômenos. Nos períodos próximos à abertura financeira (tanto antes como depois), tenderíamos a observar, principalmente nos países em desenvolvimento, aumento na volatilidade de algumas variáveis econômicas importantes como Produto Interno Bruto, taxa de câmbio e resultado do Balanço de Pagamentos. Entretanto, ao longo do tempo observaríamos uma tendência de reversão deste processo. Além da redução da volatilidade destas variáveis para patamares inferiores aos observados antes da integração, também deveremos observar indicadores que mostram evolução na condução da política macroeconômica como redução das taxas de inflação, redução do déficit e endividamento público, reformas institucionais e maior integração comercial.

Portanto, ao obtermos evidências de que tanto os aspectos positivos quanto os negativos da integração financeira podem ocorrer, mas em períodos de tempo distintos, o estudo contribui para a literatura na medida em que mostra que os resultados obtidos até o momento podem, em grande medida, estar corretos mesmo que apontem para conclusões distintas, simplesmente pelo fato de capturarem momentos distintos dos impactos do processo.

Quando trazemos à baila a importância do horizonte de tempo para as conclusões do modelo, fica evidente a necessidade de abandonarmos os tradicionais modelos cross-section e passarmos a trabalhar com modelos que considerem as flutuações ao longo do tempo das variáveis econômicas, ou seja, surge a necessidade de estimarmos esse processo com modelos de série de tempo ou dados de painel. A próxima seção apresenta qual será o procedimento utilizado 
para a abordagem empírica que faremos para o caso brasileiro.

\section{Estudo do caso brasileiro}

Nesta seção, levantam-se evidências de que o processo de integração do Brasil respeita a lógica descrita pelos modelos teóricos estudados. Após a abertura financeira observa-se a redução da volatilidade da taxa de crescimento da economia. Adicionalmente, ocorre uma série de alterações de política econômica após a abertura do mercado brasileiro aos fluxos de capitais internacionais.

\subsection{Histórico da Abertura Financeira do Brasil}

De acordo com Nazmi (1998), após movimentos oscilantes de incentivos e restrições a entrada de capital no Brasil no período pós-guerra, durante o governo de João Goulart, reconhecidamente um presidente com perfil nacionalista, é criada a legislação básica que governa os fluxos de capitais no Brasil até os dias de hoje. A Lei no $\mathbf{4} .131$, que foi promulgada em 1962, estava alinhada com os conceitos políticos do presidente, e tinha o objetivo de reduzir o papel do capital estrangeiro no País. Essencialmente, a legislação exigia que o capital estrangeiro fosse registrado para que tivesse o direito de ser remetido para o exterior, mediante pagamento de impostos, além da imposição de limites como o teto de $10 \%$ do lucro remetido para o exterior, conforme Goldfajn e Minella (2005).

Após o golpe militar de 1964, a orientação da política econômica muda e passa a estimular a entrada de capitais estrangeiros, reduzindo restrições à remessa de lucros, oferecendo garantias contra desvalorização cambial, e redução de impostos. Política que praticamente dobrou o volume de Investimento Direto Estrangeiro (IDE). Entretanto, de maneira geral, o permanente problema de Balanço de Pagamentos do País e a cultura nacionalista mantiveram em vigor uma legislação pouco amigável ao capital estrangeiro. Mesmo após o final das administrações militares, em 1986, esta lógica fica consolidada na constituição de 1988, que cria "salvaguardas" contra o capital estrangeiro. $\mathrm{O}$ art. 321 permite que o capital estrangeiro seja nacionalizado "por meios e formas a serem definidas" mediante aprovação do congresso nacional. $\mathrm{O}$ art. 322 , por sua vez, cria um novo teto à remessa de lucros e obriga as empresas multinacionais a informarem o valor exato do valor remetido.

Ainda segundo Goldfajn e Minella (2005), a primeira mudança significativa na legislação orientada para o relaxamento das restrições aos fluxos de capitais ocorreu em 1987, quando a entrada de capitais passou a ser permitida através de empresas de investimento estrangeiras, fundos de investimento de capital estrangeiro, e portfólios de ações e títulos (os chamados Anexos I e II). Outras mudanças se seguiram, sendo que um ponto de inflexão ocorre em 1991, quando investidores institucionais estrangeiros ficam liberados para 
operarem no mercado de securities (o chamado Anexo IV).

Além desta, outras alterações importantes ocorreram no início da década de 90 como: (1) redução no imposto sobre a remessa de lucros e dividendos; (2) permissão para a utilização de títulos da dívida externa do governo federal denominados em moeda estrangeira no Programa Nacional de Privatizações; (3) autorização para investidores estrangeiros representados por fundos, companhias de investimento, e investidores institucionais a operarem nos mercados de opções e futuros para securities, câmbio e taxas de juros; e (4) autorização para a emissão no exterior de debêntures e Depositary Receipts representando Securities brasileiras, como ADR (American Depositary Receipts).

Goldfajn e Minella (2005) destacam que a criação das chamadas contas CC5, permitindo a conversão de recursos em moeda doméstica para valores equivalentes em moeda estrangeira através de contas de não-residentes, iniciadas no final de 1988, marcam um momento importante de mudança legal. Ainda que transações desta natureza já fossem permitidas desde a década de 60 para os recursos externos não sacados (oriundos de vendas em moeda estrangeira), a legislação não estabelecia claramente o que poderia ser feito com os recursos de outras fontes. Só em 1993 o Banco Central do Brasil edita uma regulamentação tornando essa questão clara, flexibilizando as transferências de recursos para fora do País através de instituições financeiras não-residentes, desde que registrados os valores superiores a U\$ $\$ 10.000$ no Banco Central do Brasil. Esse mecanismo de transferência foi chamado de Transferências Internacionais em Reais (TIR) ${ }^{6}$.

Esse mecanismo representou uma mudança crucial na regulação da conta de capitais do Brasil. De um sistema que estabelecia limites rígidos para a conversão de moeda, restringindo a agentes estrangeiros e saídas relacionadas a entradas de capitais anteriores, o País passou para um sistema muito mais permissivo, estendendo esta possibilidade para os residentes. Os autores, se referindo a Franco e Pinho-Neto (2004), apontam esta mudança como sendo o momento em que o País passa a ter conversibilidade de fato.

Entre 1993 e 1995, em função do aumento expressivo do fluxo de entrada de capitais estrangeiros no País, medidas restritivas foram gradualmente sendo reintroduzidas como, por exemplo, imposto sobre ingresso de recursos, principalmente os de curto prazo. Para Golfanj e Minella (2005), estas restrições só foram completamente eliminadas em $1999^{7}$.

Outros autores discordam destas datas. Para Kaminsky e Schmukler (2003), o

\footnotetext{
${ }^{6}$ Na prática, residentes no Brasil poderiam depositar recursos em moeda local em um banco e pedir para que esta instituição financeira não-residente convertesse o recurso em moeda estrangeira e o depositasse em uma conta fora do país.

${ }^{7}$ Apesar deste amplo processo de liberalização ocorrido nos anos 1990, Arida, Bacha e Lara-Resende (2004, apud GOLDFAJN; MINELLA, 2005), destacam que o sistema resultante não poderia ser chamado de livre de restrições ou com livre conversibilidade, uma vez que todo o arcabouço legal está amparado em normativas do Banco Central e não em Lei. Desta forma, o processo pode sofrer reversões a qualquer momento.
} 
processo de liberação do mercado financeiro deve ser analisado considerando três aspectos regulatórios: (1) conta de capital, (2) setor financeiro doméstico e (3) mercado acionário. Segundo os autores, o Brasil seguiu os seguintes passos: no que se refere à regulamentação da conta de capitais, o país sofreu processos de desregulamentação e aumento de regramentos ao longo do tempo. Após muitos anos de restrições ao fluxo de capitais, em 1990, o Brasil autorizou que algumas instituições financeiras fossem habilitadas a obter recursos estrangeiros através da emissão de commercial papers. Bancos brasileiros podiam emitir certificados de depósito de médio e longo prazo. Entretanto, recursos tomados por empresas ainda precisavam respeitar um "período mínimo de maturação" de um ano. Na seqüência, outras ações ampliaram a flexibilização dos fluxos de capitais, como autorização para que investidores estrangeiros operassem em mercados de opções e futuros.

Em janeiro de 1994, o processo sofre uma reversão, com a proibição da possibilidade de contração de dívida externa automática. Além disso, a renovação ou extensão de operações de crédito anteriores ficam sujeitas a contratos com período mínimo de 36 ou 96 meses, conforme a regra aplicada para os novos contratos. Outras restrições são aplicadas durante o ano, como aumento do imposto para operações financeiras com o resto do mundo.

Somente a partir de março de 1995 é que se inicia outro ciclo de alterações legais com vistas à ampliação da liberdade dos movimentos de capitais, quando instituições financeiras e não-financeiras passam a ter direito a emissão de commercial papers, notas, títulos e securities no mercado internacional. Também neste período, foi reduzido o período mínimo de permanência do capital estrangeiro no País, de 36 para 24 meses. Deste momento em diante as restrições foram sendo gradualmente reduzidas, como a ampliação do prazo para contratação de dívida externa (de 24 para 36 meses), permissão para bancos operarem no mercado futuro de câmbio sem restrições, redução das taxas para entrada de capital e abolição do regime especial de câmbio.

Por sua vez, a regulamentação do setor financeiro nacional já vinha, há algum tempo, sendo transformada e direcionada para a redução das restrições legais ao livre funcionamento do mercado. Em 1976, os limites impostos às taxas de juros aplicadas em depósitos e empréstimos foram removidos, mas reintroduzidos em 1979. Estas foram abolidas definitivamente em 1989.

No mercado acionário brasileiro, algumas restrições passaram a operar a partir de 1973, como a necessidade da intermediação com o resto do mundo ser feita por fundos de investimento brasileiros e do capital permanecer no País por, pelo menos três anos. As remessas de lucros e dividendos também ficam sujeitas a limitações. Apesar das restrições de tempo de permanência do capital serem gradativamente reduzidas, o mercado só pode ser considerado totalmente liberalizado com a alteração da legislação ocorrida em junho de 1991, quando a necessidade de que as operações no mercado acionário bra- 
sileiro fossem feitas por fundos domésticos foi abolida.

Consolidando esses três conjuntos de informações, Kaminsky e Schmukler (2003) assumem que o Brasil teve seu mercado de capital totalmente liberalizado a partir de junho de 1991, sofrendo um revés em dezembro de 1993 e voltando a ser totalmente livre a partir de março de 1995.

Segundo Van der Laan et al. (2007), as principais medidas no sentido de liberalização da conta de capital foram construídas de forma independente entre si, cada qual tratando de um aspecto específico da regulamentação cambial, sendo por fim consolidada no novo Regulamento do Mercado de Câmbio e Capitais Internacionais em março de 2005 (RMCCI).

Apesar de alguma divergência na determinação do momento exato em que o País passa a permitir fluxos mais livres de capital, essencialmente o grande período de quebra de paradigma ocorre nos primeiros anos da década de 1990. Para Goldfajn e Minella (2005), o ano de 1993 marcaria este momento. Para Kaminsky e Schmukler (2003) esta data seria 1991, mas reconhecendo que há uma reversão do processo até 1995. Por fim, Bekaert et al. (2005) indicam que a data seria 1991, período em que o país emite seus primeiros ADRs.

Para os testes desenvolvidos neste artigo, considerar-se-á o ano de 1991 como o período de liberação plena dos fluxos de capitais. Esta escolha se deve a dois motivos: (1) permitir um número maior de observações no período considerado como livre de restrições, e (2) por incorporar um período em que movimentos de ampliação e redução do grau de abertura do mercado financeiro brasileiro, esta escolha torna mais robustos os resultados que confirmem a queda da volatilidade do produto.

\subsection{Volatilidade do Produto Interno Bruto antes e após a Abertura Financeira}

O objetivo desta seção é investigar se o processo de integração financeira ocorrido no país no início dos anos 90 colaborou para a redução da volatilidade da taxa de crescimento do PIB. Além disso, apresentar-se-ão evidências de que a integração financeira também precedeu mudanças na condução da política macroeconômica nacional, indicando que a abertura financeira pode ser uma fonte importante de indução à adoção de políticas econômicas pró-mercado.

\subsubsection{Evoluçãodasmudançasinstitucionaisepolíticas noBrasil}

As principais características da economia brasileira, sob o ponto de vista de regras institucionais e políticas, desde o início da década de 80 até os dias atuais, são brevente discutidas abaixo. A análise histórica nos permite subdividir os últimos 29 anos da economia brasileira em quatro sub-períodos, sendo que cada um deles incorpora ao menos uma grande mudança de política 
econômica, conforme apresentado no quadro 1.

O primeiro período, portanto, vai de 1980 até o final do ano de 1990, e é caracterizado por uma economia fechada, tanto do ponto de vista comercial como financeiro, com regime cambial crawling peg passivo, profundos desequilíbrios fiscais e elevado nível instabilidade de preços.

O segundo período, entre 1991 e meados de 1994, mantém as mesmas características do período anterior, exceto pelo nível de integração com o resto do mundo, iniciando um processo de abertura comercial e consolidando o processo de integração financeira, de acordo com as análises de Kaminsky e Schmucler (2003) e Bekaert at al. (2005). Entretanto, são mantidas as políticas fiscal e monetária.

QUADRO 1 - CLASSIFICAÇÃO DAS MUDANÇAS INSTITUCIONAIS E POLÍTICAS NO BRASIL

\begin{tabular}{|l|l|}
\hline Períodos & Mudanças institucionais e políticas \\
\hline 1980.I - 1990.IV & $\begin{array}{l}\text { Economia fechada } \\
\text { Regime cambial crawling peg passivo } \\
\text { Déficit Fiscal } \\
\text { Instabilidade de preços }\end{array}$ \\
\hline 1991.I - 1994.II & $\begin{array}{l}\text { Abertura econômica (comercial e financeira) } \\
\text { Regime cambial crawling peg passivo } \\
\text { Déficit Fiscal } \\
\text { Instabilidade de preços }\end{array}$ \\
\hline $\begin{array}{l}\text { 1994.III - 1999. } \\
\text { IV }\end{array}$ & $\begin{array}{l}\text { Economia aberta } \\
\text { Regime cambial de bandas cambiais e } \\
\text { crawling peg ativo } \\
\text { Estabilidade de preços (Plano Real) } \\
\text { Programa de Ajuste Fiscal (renegociação das } \\
\text { dívidas dos Estados) } \\
\text { Privatizações }\end{array}$ \\
\hline 2000.I - 2009.II & $\begin{array}{l}\text { Economia aberta } \\
\text { Regime de câmbio flutuante } \\
\text { Estabilidade de preços } \\
\text { Lei de Responsabilidade Fiscal }\end{array}$ \\
\hline
\end{tabular}

Fonte: Elaboração dos autores. 
O terceiro período, entre o terceiro trimestre de 1994 e o final de 1999, adiciona outras mudanças significativas no que tange a medidas de política econômica. A primeira grande alteração é o início do Plano Real e, a partir daí, da estabilidade de preços. Em seguida adota-se um regime de câmbio fixo, mas com algum grau de flutuação dentro de "bandas" definidas pelo governo. Além disso, inicia-se um amplo processo de ajuste fiscal através da renegociação das dívidas dos estados. Este processo foi importante para reduzir o grau de insegurança quanto à capacidade do Estado de pagar suas dívidas, na medida em que estanca uma das principais fontes de endividamento público. Por fim, os governos aceleram o processo de privatização no País, tanto pela necessidade de obter recursos adicionais para financiar o déficit fiscal ainda persistente como por uma mudança de visão do papel dos setores até então monopolizados pelo Estado para o desenvolvimento da economia brasileira.

O último período selecionado vai desde o início do ano de 2000 até os dias atuais e é caracterizado pela manutenção da economia aberta aos fluxos de capitais e de comércio, e da estabilidade de preços. No entanto, duas alterações importantes ocorrem. A primeira é a adoção do regime de câmbio flutuante (mais especificamente de flutuação suja) e da entrada em vigor da Lei de Responsabilidade Fiscal, ou seja, os governos passam a adotar medidas mais rigorosas de controle dos desequilíbrios entre receitas e despesas.

Cabe observar que os processos de abertura comercial e financeira são os primeiros a ocorrer no período analisado, ou seja, precedendo todas as demais alterações de políticas registradas. O comportamento da economia brasileira, de certa forma, reforça a conclusão obtida por Henry (2000a), que diz que a abertura financeira coincide com quatro reformas: (1) estabilização macroeconômica, (2) abertura comercial, (3) privatizações e (4) redução de controles de câmbio.

\subsubsection{Análise de mudanças na variabilidade do cresci- mento econômico}

O Gráfico 1, abaixo, apresenta o comportamento da taxa de crescimento do PIB brasileiro, acumulada em períodos de dez anos, entre 1980 e o segundo trimestre de 2009.

O gráfico 1 mostra um aumento da taxa de crescimento média ao longo do período analisado. Podemos ver que a taxa média de crescimento nos últimos dez anos da amostra fica em aproximadamente $2,3 \%$ ao ano, enquanto nos dez anos anteriores alcança $1,3 \%$. Ou seja, a taxa média de crescimento praticamente dobra no período analisado.

A análise de variabilidade foi realizada a partir do cálculo do desvio-padrão de duas variáveis que expressam o comportamento de curto prazo do PIB: a taxa 
de crescimento trimestral do PIB e o componente de ciclo econômico do PIB decomposto pelo filtro Hodrick-Prescott (HP). O desvio-padrão foi calculado para sub-períodos específicos, associados à classificação definida no Quadro 1.

\section{GRÁFICO 1 - TAXA DE CRESCIMENTO DO PIB ACUMULADA POR PERÍODOS DE DEZ ANOS}

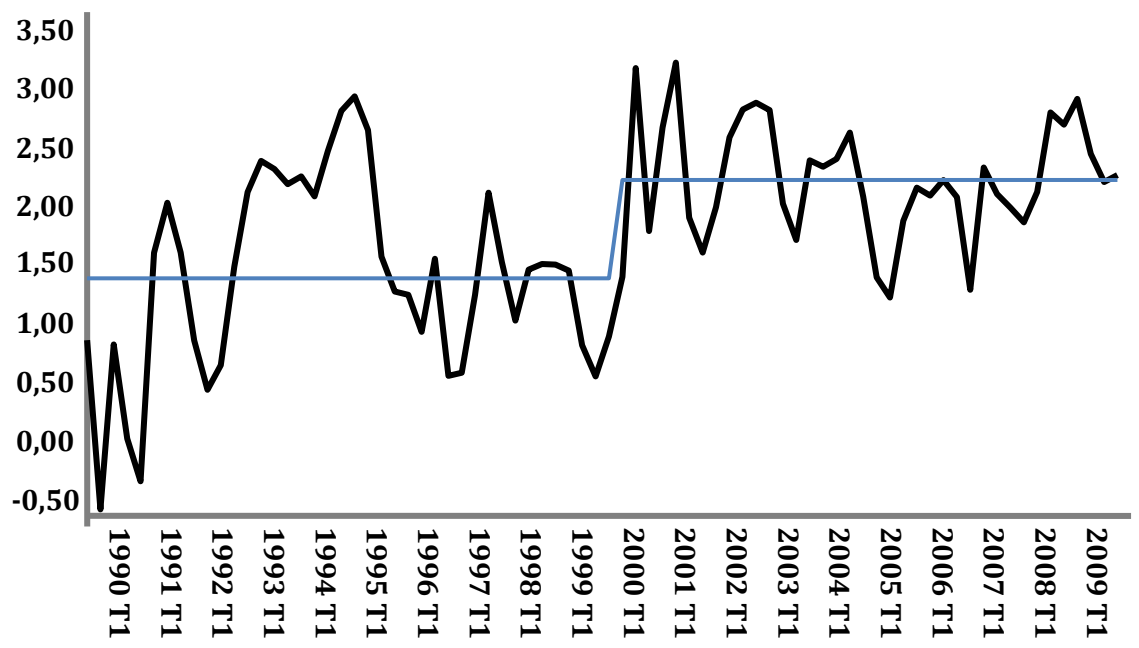

Fonte: Ipeadata. Elaboração dos autores.

O filtro $\mathrm{HP}^{8}$ consiste num método de suavização usualmente utilizado para decompor os componentes de tendência (longo prazo) e ciclo (curto prazo) de séries econômicas. Considerando $s_{t}$ o componente suavizado (tendência) da série $y_{t}$, o filtro HP minimiza a variância entre $y_{t}$ e $s_{t}$. Formalmente, o filtro HP escolhe $s_{t}$ que minimiza a seguinte expressão dada pela equação abaixo:

$$
\sum_{t=1}^{T}\left(y_{t}-S_{t}\right)^{2}+\lambda \sum_{t=2}^{T-1}\left(\left(S_{t+1}-S_{t}\right)-\left(S_{t}-S_{t-1}\right)\right)^{2}
$$

O parâmetro $\lambda$ define o grau de suavidade da série. Os componentes tendência e ciclo calculados a partir do filtro HP para a série trimestral do PIB brasileiro são apresentados no Gráfico 2. 
Em seguida, procedemos à análise de variância dos quatro sub-períodos considerados:
1) $1980 . I-2009 . I I$
2) 1991.I - 2009.II
3) 1994.III - 2009.II
4) $2000 . I-2009 . I I$

\section{GRÁFICO 2 - DECOMPOSIÇÃO ${ }^{9}$ DOS COMPONENTES TENDÊNCIA E CICLO A PARTIR DO FILTRO HODRICK-PRESCOTT}

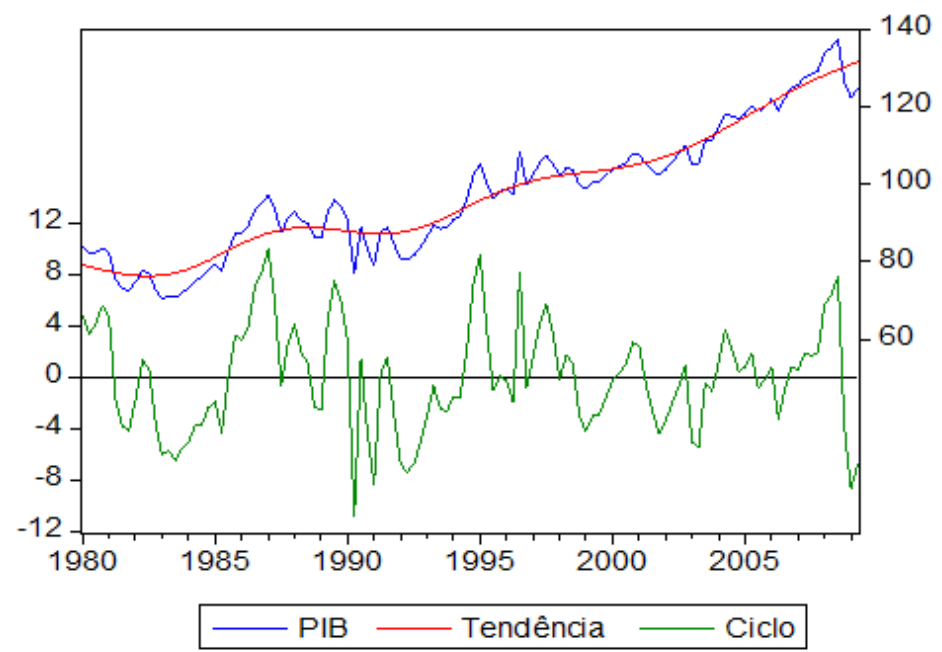

Fonte: Elaboração dos autores.

O período 1980.I - 2009.II compreende todo o período amostral, de modo que a variabilidade econômica neste intervalo necessariamente refletirá a variabilidade de diferentes regimes institucionais e de políticas econômicas. Para os demais sub-períodos, o ponto inicial muda conforme o ponto inicial do Quadro 1, mantendo-se o ponto final em 2009.II. De acordo com os pressupostos teóricos, espera-se que a variabilidade econômica seja decrescente nesses subperíodos se as mudanças institucionais e de políticas econômicas promovidas no intercurso dos mesmos melhoraram a eficiência do sistema econômico. 
Os resultados apontados nos gráficos 3 e 4 indicam que houve uma redução contínua da variabilidade econômica no Brasil ao longo desse período.

O desvio padrão do crescimento do PIB no período 2000.I-2009.II foi $38 \%$ menor que aquele observado ao longo do período como um todo (1980.I-2009. II). Quando comparamos a volatilidade entre o período completo e o que compreende intervalo entre 1991 e 2009, já temos uma queda de 16\%. Isso representa quase a metade do total da redução ocorrida em todo o período considerado. A queda ocorrida a partir de 1994.II foi somente de 5\%, representando pouco mais do que $12 \%$ do total da redução, ou seja, sinalizando que as novas políticas adotadas contribuíram marginalmente menos para a redução da volatilidade do que as introduzidas no período anterior (entre 1991 e 1994). Já o período iniciado em 2000.I também registra outra forte queda da volatilidade (17\%) representando aproximadamente $44 \%$ do total da redução registrada. Assim, aparentemente as políticas adotadas no início da década de 90 e a partir do ano 2000 foram as que mais contribuíram para a redução da volatilidade do PIB.

\subsection{0}

GRÁFICO 3 - DESVIO PADRÃO DA TAXA DE CRESCIMENTO DO PIB POR PERÍODOS SELECIONADOS

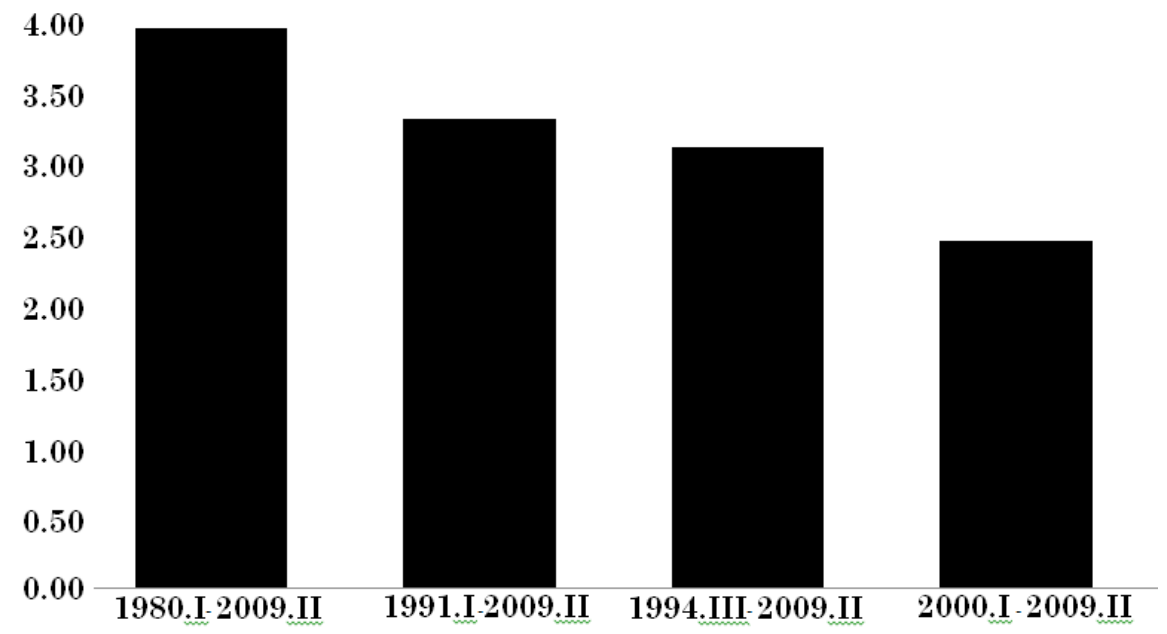

Fonte: Elaboração dos autores.

No caso do desvio-padrão do ciclo HP, a redução foi de 17,7\%, como mostrado no Gráfico 4, abaixo. Aqui também observamos que praticamente a metade da redução do desvio-padrão registrada ocorre já a partir de 1991, ou seja, o período que incorpora a abertura financeira. $\mathrm{O}$ dois subperíodos posteriores contribuem com $24 \%$ e $27 \%$ do total da redução ocorrida, respectivamente. 
A análise preliminar dos dados indica, portanto, que houve uma mudança no comportamento da volatilidade do PIB. O passo seguinte é testar se esta mudança observada é estatisticamente significativa.

Utilizamos um modelo GARCH $(2,3)^{10}$ para estimar a variância da série trimestral do PIB brasileiro e buscamos investigar se o padrão de variância sofreu mudanças significativas ao longo do período 1980.I-2009.II, especialmente com respeito aos subperíodos definidos no Quadro 1.

\section{GRÁFICO 4 - DESVIO PADRÃO DO CICLO HP DO PIB POR PERÍODO SELECIONADO}

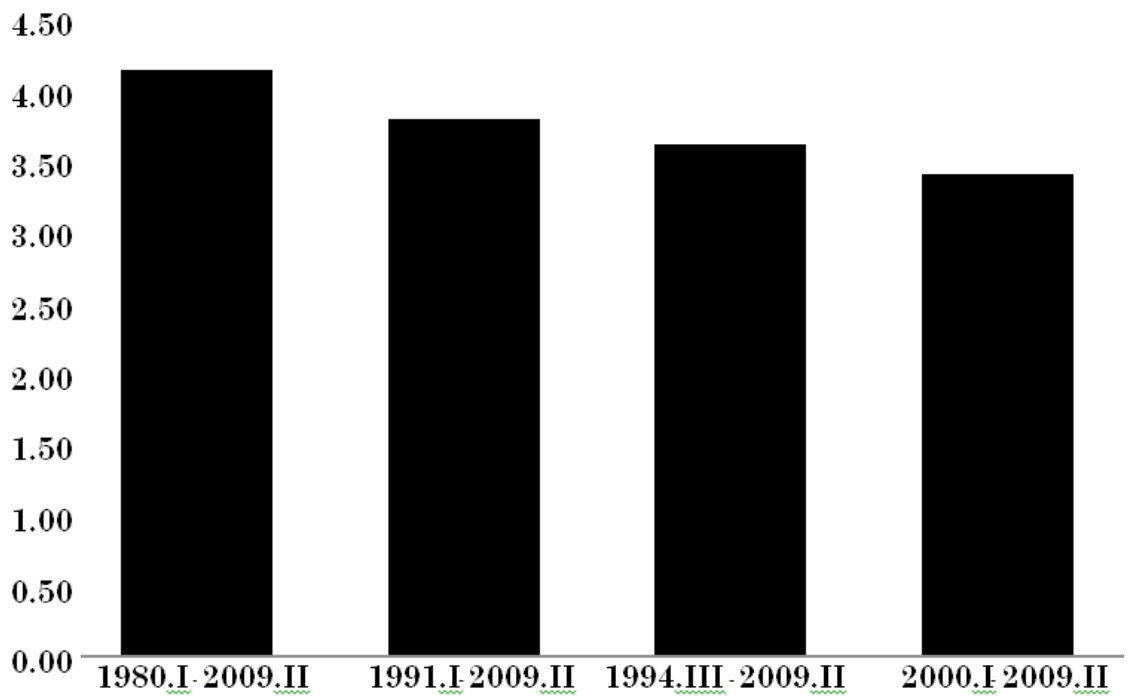

Fonte: Elaboração dos autores.

Modelos GARCH são usualmente empregados para análise de séries financeiras, mas também podem ser aplicados para séries não financeiras. No caso do presente exercício, o objetivo é avaliar alterações significativas na variabilidade do PIB brasileiro que estariam associadas ao processo de abertura financeira e econômica e outras mudanças institucionais e de políticas econômicas que ocorreram no País posteriormente ao processo de abertura financeira, portanto, este modelo se mostra o mais apropriado.

${ }^{10}$ Essa ordem de defasagem dos componentes GARCH foi definida a partir dos critérios de informação de Akaike e Schwartz. Tendo em vista que os dados são trimestrais, optou-se por uma ordem máxima para p e q de 4 defasagens, possibilitando capturar uma memória referente a um ano para trás. Os resultados dos critérios de informação de Akaike e Schwartz podem ser encontrados no Anexo. 
Para uma série $\mathrm{y}_{\tau}$ qualquer, a estrutura básica do modelo GARCH é a seguinte:

$$
\begin{gathered}
y_{t}=\delta+\varepsilon_{t} \\
\sigma_{t}^{2}=\omega+\sum_{i=1}^{\rho} \alpha_{i} \varepsilon_{t-1}^{2}+\sum_{j=1}^{q} \beta_{i} \sigma_{t-j}^{2}
\end{gathered}
$$

A primeira expressão representa a equação da média da variável, enquanto a segunda representa a equação da variância. Para efeito da análise, serão estimados os seguintes modelos:

Modelo 1: estimação do modelo básico com a ordem $(p, q)$ mais apropriada conforme os critérios de informação de Akaike e de Schwartz. A ordem máxima para $p$ e $q$ será 4 ;

Modelo 2: estimação do Modelo 1 acrescentando a variável Bekaert na equação da variância, a qual é uma variável dummy para capturar efeitos da abertura financeira (possui valor 1 para o período 1991.I-2009.II);

Modelo 3: estimação da estrutura do Modelo 1 acrescentando três variáveis dummies respectivas aos períodos classificados na Tabela 1. Essas variáveis possuem a seguinte especificação:

D91_94 = 1 no período 1991.I-1994.II e o no caso contrário

D94_99 = 1 no período 1994.II-1999.IV e o no caso contrário

Doo_09 = 1 no período 2000.I-2009.II e o no caso contrário

Modelo 4: estimação da estrutura do Modelo 3 acrescentando a taxa de crescimento do PIB da OCDE (proxy do crescimento mundial) como variável explicativa na equação da média.

A estimação do Modelo 4 permite controlar efeitos de mudança na variância do PIB brasileiro associados a mudanças na variância do PIB mundial. Se existir um padrão de redução da variância do PIB nacional correlacionado com a redução da variância do PIB mundial, esse efeito pode ser controlado nessa especificação.

As dummies adicionadas no modelo 3 buscam capturar se o conjunto de mudanças nos instrumentos de política econômica ocorridos em cada um dos sub-períodos pode explicar, ao menos, parte do comportamento da volatilidade do PIB.

Os resultados dos parâmetros estimados para esses modelos são apresentados na Tabela 1, a seguir. Os resultados do Modelo 2 mostram que a variável Bekaert (dummy com valor 1 a partir de 91) não é estatisticamente significativa, embora tenha sinal negativo conforme esperado pela teoria e pela análise exploratória da seção anterior. Esse resultado indica que a variável que captura 
o período completo em que o país é considerado integrado financeiramente não explica isoladamente a alteração do padrão de volatilidade do PIB $^{11}$.

No entanto, as variáveis dummies D91_94 e Doo_94 se mostraram estatisticamente significativas, tanto no Modelo 3 como no Modelo 4. Isso indica que houve uma redução significativa e não linear na variância do crescimento do PIB nacional posterior à abertura financeira e comercial e posterior ao processo de estabilização e flexibilização cambial. Ressalta-se que esse resultado é robusto mesmo quando se considera a taxa de crescimento dos países da OCDE na equação da média do PIB nacional. Neste caso, o que ocorre é apenas uma pequena redução nos valores dos parâmetros dessas variáveis dummies.

TABELA 1 RESULTADOS DAS REGRESSÕES GARCH

\begin{tabular}{l|c|c|c|c}
\hline & Modelo 1 & Modelo 2 & Modelo 3 & Modelo 4 \\
\hline Equação da média & & & \\
\hline Constante $\quad 0,5495 * *$ & $0,7141 * *$ & $0,7729 * * *$ & $-0,4573$ \\
PIBOCDE & & & $2,1184 * * *$ \\
\hline
\end{tabular}

\section{Equação da variância}

$\begin{array}{lllll}\text { Constante } & 6,2518 * * & 6,0817 * & 23,4420 * * & 14,8174 * * * \\ \varepsilon_{t-1}^{2} & 0,2314 * * * & 0,2105 * * * & 0,2052 * & 0,4704 * * \\ \varepsilon_{t-2}^{2} & 0,2337 * * * & 0,0105 & 0,1779 * & 0,3498 \\ \sigma_{t-1}^{2} & -0,8497 * * * & 0,0777 & -0,8813 * * * & -0,6660 * * \\ \sigma_{t-2}^{2} & 0,2229 * & -0,2334 * * * & 0,1421 & 0,1607 \\ \sigma_{t-2}^{2} & 0,6746 * * * & 0,6377 * * * & 0,2361 & 0,0595\end{array}$

Bekaert $-3,1683$

D91_94

D94_99 $-2,7038$ $-1,1251$

D00_09 $-15,7710 * \quad-11,3083 * * *$

AIC

5,3903

5,4550

5,4388

5,3138

SIC

5,5583

5,6470

5,6788

5,5808

* Significante a $10 \%$. ** Significante a $5 \%$. *** Significante a $1 \%$.

Fonte: Elaboração dos autores.

${ }^{11}$ Algumas especificações alternativas acabam confirmando a significância desta variável, mas os resultados não demonstram estabilidade. 
Estes dois resultados combinados indicam que, em conjunto, as mudanças ocorridas entre 1991.I e 1994.II, estão negativamente correlacionadas com a volatilidade do PIB. Este resultado, associado ao encontrado pelo modelo 2, indicam que a abertura financeira, não parece ser o fator mais relevante para explicar esse comportamento. Isso reforça a idéia de que a abertura comercial ocorrida no mesmo período pode ter sido mais relevante para a redução da volatilidade do PIB. O certo, no entanto, é que há indícios de que a integração econômica (financeira e comercial) ocorrida no período foi capaz de reduzir a oscilação da taxa de crescimento do produto.

Da mesma forma, o resultado obtido para a dummy do período 2000.I 2009.II indica que o conjunto de alterações ocorridos nos instrumentos de política econômica na última década também parecem ter contribuído para uma redução significativa na volatilidade do PIB.

\section{Considerações finais}

O artigo proposto iniciou apresentando as divergências teóricas acerca da capacidade da integração financeira gerar impactos positivos nas economias emergentes, principalmente no que se refere à aceleração da taxa de crescimento do PIB (efeitos diretos). Enquanto alguns autores, como Rodrik (1998), defendem que este processo não gera resultados positivos no que concerne ao crescimento e que, além disso, provoca crises financeiras, outros autores, como Krugman (2002) e Kose et al. (2006) defendem a idéia de que esse processo provoca benefícios por múltiplos canais.

Estes autores defendem que a integração financeira pode ser uma fonte de instabilidade econômica a curto prazo, mas que após algum tempo de adaptação seus efeitos são altamente benéficos e seriam evidentes tanto através do aumento das taxas de crescimento quanto da redução da volatilidade das taxas de crescimento, por exemplo.

A confirmação desta visão fecha uma lacuna importante da literatura acerca dos impactos da integração financeira. Ela reconcilia duas linhas de argumentação aparentemente contraditórias. A primeira que aponta para aceleração das taxas de crescimento de longo prazo de países integrados nos seus mercados de capitais, e a segunda que aponta para a ocorrência de crises financeiras nos países em desenvolvimento que se engajaram neste movimento. Entretanto, a hipótese defendida aqui é que ambas podem estar corretas, mas cada uma contando uma parte apenas da história. O que tenderia a ocorrer nos países em desenvolvimento é uma grande oscilação das taxas de crescimento nos períodos subseqüentes à abertura de capital (período de crise), mas um aumento das taxas de crescimento e redução desta volatilidade após algum tempo de adaptação (efeitos positivos de longo prazo). 
O que buscamos fazer no presente estudo foi testar se o caso brasileiro pode ser relacionado como um exemplo deste processo de crise e adaptação ao mercado de capitais integrado a longo prazo. Ou seja, será que o processo de integração financeira do Brasil, iniciado em 1991, pode servir como referência na defesa da tese de que a abertura financeira tende a trazer benefícios de longo prazo às economias em desenvolvimento que se engajam neste processo?

Para tanto, iniciamos analisando o comportamento da volatilidade do PIB trimestral entre 1980.I e 2009.II, reconhecendo que ao longo deste período ocorreram alterações significativas na condução da política econômica brasileira. Em função disto, subdividimos este intervalo de tempo em quatro subperíodos, cada um incorporando ao menos uma mudança institucional ou de política econômica relevante. Os resultados indicaram uma redução sistemática da volatilidade do PIB brasileiro após 1991, período a partir do qual o País é considerado financeiramente integrado com o resto do mundo.

Além disso, o resgate histórico registra que uma série de mudanças de política econômica ocorreu após este período. Entre elas destacam-se o controle da inflação (a partir de 1994), mudança do regime cambial (a partir de 1999) e maior responsabilidade fiscal (a partir de 2000). Todas estas alterações ocorrem em um intervalo de 10 anos, após décadas de desequilíbrios. Essa observação reforça a tese de Henry (2000a) e Kaminsky e Schmukler (2003), de que a integração financeira tende a estimular reformas pró-mercado.

Por fim, este artigo testou, através de um modelo GARCH, se as mudanças observadas na volatilidade de cada subperíodo eram estatisticamente significantes. Os resultados indicaram que as mudanças de padrão de variação do produto observadas entre os períodos de 1991.I e 1994.II e de 2000.I e 2009. II são significativas. Para reforçar o resultado, estimou-se outra equação incluindo a variação do PIB da OCDE como proxy da variação do PIB mundial, para testarmos se a mudança da volatilidade do PIB brasileiro estava sendo influenciada primordialmente por fatores externos. $\mathrm{O}$ resultado mostra que os fatores externos são importantes para explicar o comportamento da volatilidade do PIB brasileiro, mas os fatores internos, capturados pelas dummies dos referidos intervalos se mantém significativas.

\section{Referências bibliográficas}

Bekaert, G.; Harvey, C.; Lundblad, C. (2005). "Does financial liberalization spur growth?”. Journal of Financial Economics, n. 77, p. 3-35.

Bruno, M.; Easterly, W. (1998). "Inflation crises and long run growth”. Journal of Monetary Economics, v. 1 (41), p. 3-26.

Bussiere, M.; Fratzscher, M. (2004). "Financial openness and growth: short-run gain, long-run pain?”. ECB Working Paper, n. 348. 
STELLA, M.A.; HILLBRECHT, R.O.; PORSSE, A. A. Impactos colaterais da integração financeira......

Calvo, G.; Végh, C. (1998). "Inflation stabilization and balance of payments crises in developing countries”. In: TAYLOR, J.; WOODFORD, M. (Ed.). Handbook of Macroeconomics. North-Holland, 1998.

Cardoso, E.; Goldfajn, I. (1998). "Capital flows to Brazil: the endogeneity of capital controls”. IMF Staff Papers, v. 45 (1), p. 161-202.

Carvalho, B.; Garcia, M. (2006). "Ineffective controls on capital inflows under sophisticated financial markets: Brazil in the nineties”. NBER Working Paper n. 12283.

Cipriani, M.; Kaminsky, G. (2006). "Volatility in international financial market issuance: The role of the financial center". NBER Working Paper n. 12587.

Easterly, W. (1996). "When is stabilization expansionary?”. Economic Policy, n. 22, p. 67-107.

Edison, H. et al. (2004). "Capital account liberalization, and economic performance: synthesis and survey”. IMF Staff Papers, v. 51 (2), p. 220-56.

Edwards, S. (2004). "Financial openness, sudden stops and current account reversals”. NBER Working Paper, n. 10277.

Eichengreen, B. (2001). "Capital account liberalization: what do cross-country studies tell us?”. The World Bank Economic Review, v. 16 (3), p. 341-65.

Feenstra, R.; Taylor, A. (2008). International macroeconomics. New York: Worth Publishers.

Fisher, S. (1998). "Capital account liberalization and the role of the IMF". Princeton Essays in International Finance, n. 207, p. 1-10.

Fisher, S.; Sahay, R.; Végh, C. (2002). "Modern hyper and high inflations”. Journal of Economic Literature, v. 3 (40), p. 937-80.

Franco, G.; Pinho-Neto, D. (2004). “A desregulamentação da conta de capitais: limitações macroeconômicas e regulatórias”. Texto para Discussão: PUC-RJ, no. 479.

Frankel, J.; Romer, D. (1999). “Does trade cause growth?”.American Economic Review, v. 3 (89), p. 379-99.

Garcia, M.; Barcinski, A. (1998). "Capital flows to Brazil in the nineties: Macroeconomic aspects and the effectiveness of capital controls". Quarterly Review of Economics and Finance, v. 38 (3), p. 319-57.

Garcia, M.; Valpassos, M. (1998). "Capital flows, capital controls and currency crisis: The case of Brazil in the nineties". Texto para discussão: PUC-RJ, n. 389.

Goldfajn, I.; Minella, A. (2005). "Capital controls and flows in Brazil: What have we learned?”. NBER Working Paper, n. 11640.

Henry, P. (2000a). "Stock market liberalization, economic reform, and emerging market equity prices”. Journal of Finance, v. 55 (2), p. 529-64.

Henry, P. (200ob). "Do stock market liberalization cause investment booms? ". Journal of Financial Economics, v. 58 (1-2), p. 301-34.

Henry, P. (2006). "Capital account liberalization: theory, evidence, and speculation". NBER Working Paper, $n .12698$.

Henry, P.; Sasson, D. (2008). "Capital account liberalization, real wages, and productivity”. NBER Working Paper, n. 13880. 
STELLA, M.A.; HILLBRECHT, R.O.; PORSSE, A. A. Impactos colaterais da integração financeira......

Hodrick, R; Prescott, E. (1997). "Postwar U.S. business cycles: An empirical investigation. Journal of Money, Credit, and Banking”, n. 29, p. 1-16.

Kaminisky, G.; Schmukler, S. (2003). "Short-run pain, long-run gain: the effects of financial liberalization”. NBER Working Paper, n. 9787.

Kaminsky, G.; Reinhart, C. (1998). “The twin crises: the causes of banking and balance of payments problems". The American Economic Review, v. 89 (3), p. 473-500.

Kose, M. et al. (2006). "Financial globalization: a reappraisal". NBER Working Paper, n. 12484.

Kose, M.; Prasad, E.; Taylor, A. (2009). “Thresholds in the Process of International Financial Integration”. NBER Working Paper, n. 14916.

Krueger, A. (1997). “Trade policy and economic development: How we learn”. American Economic Review, v. 1 (87), p. 1-22.

Krueger, A. (1998). "Why trade liberalization is good for growth". Economic Journal, n. 108, p. 1513-22.

Krugman, P. (2002). "Crises: the price of globalization? Symposium on global economic integration”. Federal Reserve Bank of Kansas City.

Martinez, L.; Tornell, A.; Westermann, F. (2004). "The positive link between financial liberalization, growth and crises”. NBER Working Paper, $n .10293$.

Mishkin, F. (2006). The next great globalization: how disadvantaged nations can harness their financial systems to get rich. Princeton University Press.

Nazmi, N. (1998). “The impact of foreign capital on the brazilian economy”. Quarterly Review of Economics and Finance, v. 38 (3), p. 483-502.

Obstfeld, M. (1998). The global capital market: benefactor or menace? Journal of Economic Perspectives, v. 12, n. 4, p. 9-30, 1998.

Pires, J. (2006). “O efeito da liberalização da conta de capital sobre a política fiscal: Uma avaliação do caso brasileiro recente”. Revista de Economia Política, v. 26 2), p. 258-73.

Prasad, E. et. al. (2003). "Effects of financial globalization on developing countries; some new evidence”. IMF Occasional Paper, n. 220.

Prasad, E.; Rajan, R.; Subramanian, A. (2006). "Foreign capital and economic growth". IMF Research Department. Mimeo.

Ranciere, R.; Tornell, A.; Westermann, F. (2006). "Decomposing the effects of financial liberalization: Crises vs. growth”. NBER Working Paper, n. 12806.

Rodrik. D. (1998). “Who needs capital account convertibility?”. Princeton Essays in International Finance, v. 207, p. 55-65.

Rogoff, K. (1999). "International institution for reducing global financial instability". Journal of Economic Perspectives, v. 13 (4), p. 21-42.

Sachs, J.; Warner, A. (1995). "Economic reforms and the process of global integration”. Brookings Papers on Economic Activity, n. 1, p. 1-95.

Summers, L. (2000). "International financial crises: causes, prevention, and cures". American Economic Review, v. 90 (2), p. 1-16.

Solow, R. (1956). "A contribution to the theory of economic growth". Quarterly 
STELLA, M.A.; HILLBRECHT, R.O.; PORSSE, A. A. Impactos colaterais da integração financeira......

Journal of Economics, n. 70, p. 65-94.

Tófoli, P.; Hillbrecht, R.; Ribeiro, E. (2008). Abertura da conta de capital e crescimento econômico: quais as evidências para o caso brasileiro. Porto Alegre: UFRGS. Mimeo.

Van Der Lann, C.; Cunha, A.; Lélis, M. (2007). Uma avaliação sobre os impactos da abertura da conta capital no Brasil (1994-2006). Mimeo.

Wacziarg, R.; Welch. K. (2003). “Trade Liberalization and growth: New evidence”. NBER Working Paper, n. 10152.

Recebido em: 21 de setembro de 2012

Aceito em: 01 de março de 2013 